\title{
Programs That Make an Impact
}
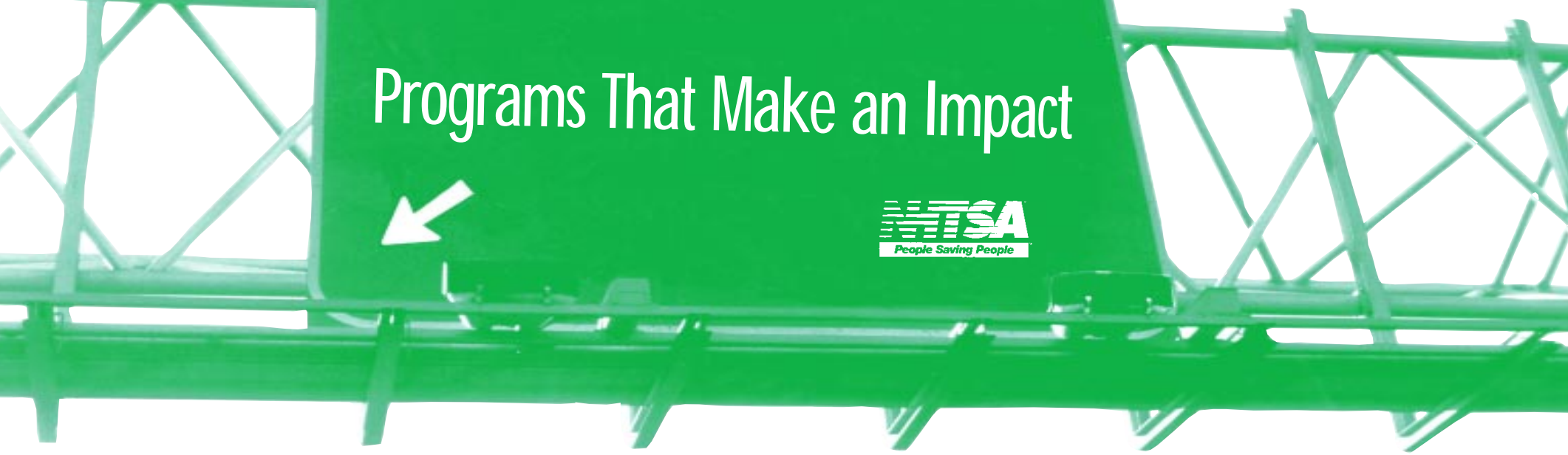

\section{MARYLAND STATE POLICE}

The State of M aryland had long enjoyed a steady decline in fatal crash rates for both vehicle miles traveled and for traffic volumes over the past several years. H ow ever, traffic fatalities increased 35 percent during the first quarter of 1995 compared to the same period in 1994.

An analysis of crash data revealed no specific reason for the dramatic increase in fatalities, but instead a variety of violations that contributed to the increase. The only type of violation that

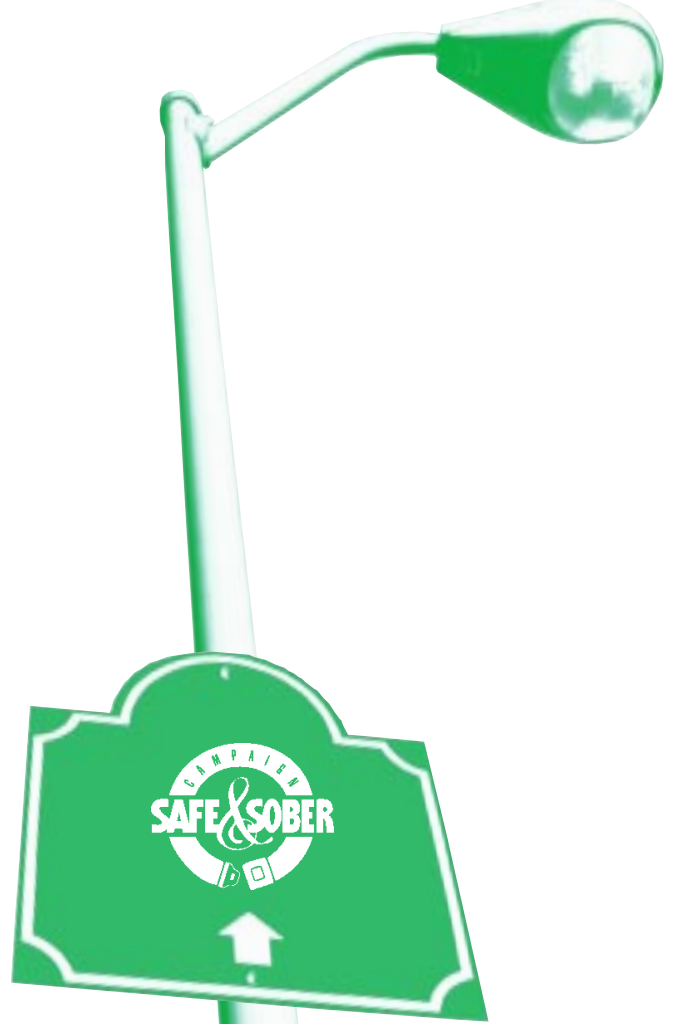
decreased was speed-related crashes. Some examples of the violations that were major contributors to fatal crashes are listed in the table below.

\begin{tabular}{|c|c|c|c|}
\hline CAUSE & $\begin{array}{l}\text { FIRST QUARTER } \\
1994 \text { FATALITES }\end{array}$ & $\begin{array}{l}\text { FIRST QUARTER } \\
1995 \text { FATALITES }\end{array}$ & $\begin{array}{l}\text { PerReNT } \\
\text { CHANGE }\end{array}$ \\
\hline SPEEDRELATED & 18 & 16 & -11 \\
\hline FALLURE TO DRVE IN SINGLE LANE & 15 & 22 & +47 \\
\hline FALLRE TO KEeP RIGHT OF CENTER & 13 & 19 & +46 \\
\hline LLEGGLYY IN ROADWAY & 5 & 7 & +40 \\
\hline INATEENTON & 9 & 18 & +100 \\
\hline Fallure to GRant Right OF WAY & 12 & 20 & +67 \\
\hline
\end{tabular}

With the above information, the M aryland State Police embarked on a new program entitled "T he A ggressive D river Campaign," which targeted these offenses. The idea was to focus on increased enforcement and public information and education with a slightly different twist.

The campaign requested the motoring public's assistance in identifying vehicles committing these offenses. This was accomplished by selling the motorists on the concept that the law enforcement effort was to target the "other motorists" who were operating motor vehicles in an erratic and unsafe manner.

In essence, the campaign did not employ the usual "we're going to get you," but a "help us get the other motorist who drives unsafely and is a danger to you" approach. Instead of the usual adversary approach, this approach created a team-like association between the motoring public and law enforcement. 
The public information and education campaign informed motorists of the increased enforcement efforts and the associated fines and penalties. Furthermore, the public was given a toll-free cellular telephone number that could be used to immediately report erratic or unsafe drivers.

While most police agencies receive negative feedback for such stringent enforcement activities, the M aryland State Police received strong accolades from the media and the public. This can be attributed to the commitment to the cause and the public's perception that the M aryland State Police are "out there catching the other guy to keep you safe."

For additional information, contact:

FIRST SGT. MICHAEL J. FISCHER

$M$ aryland State Police

1201 Reisterstown Road

Pikesville, MD 21208

Phone: (410) 653-4234

Fax: (410) 653-3293

\section{MADISON, WISCONSIN}

A program in Madison, Wisconsin, called N eighborhood Speed Watch, also involved citizens in the speed issue. The M adison

Transportation D epartment and the M adison Police Department helped citizens set up and monitor speeds on select neighborhood streets by using a speed display board borrowed from the traffic engineering staff. In effect since 1992, the program has deterred motorists from speeding and has increased voluntary compliance with speed limit laws.

For additional information, contact:

TOM WALSH

Madison Department of

Transportation

Traffic Engineering Division

M adison Municipal Building

215 Martin Luther King Boulevard

Madison, WI 53701

Phone: (608) 266-4761

\section{SOUTHEASTERN CONNECTICUT}

In 1993, law enforcement officials in eight southeastern Connecticut cities and towns met to discuss the recent traffic safety problems surrounding their region: increased traffic crashes contributing to an increase in injuries and fatalities, and a low safety belt usage rate.

Compounding these traffic safety issues was a substantial traffic flow increase attributed to a new $N$ ative A merican casino operation. The casino, located in a small, rural town, drew hundreds of thousands of visitors, which caused many problems on the single small secondary road leading to the casino. Casino activity also resulted in an increase in impaired driving, speeding, and non-use of safety belt violations. $N$ one of the local communities ben fited from the casino profits due to the sovereignty of the $\mathrm{N}$ ative A merican nation. Rather than being an economic boom to the region, the casino was imposing an economic burden on the local police departments, which lacked the resources to deal with the problems effectively.

A ffected communities, along with the Connecticut State Police, entered into a "M utual Police A ssistance Compact," which authorizes each Chief of Police or Resident Trooper to assign personnel to participate in the Southeastern Connecticut Regional T raffic U nit. Specific responsibilities for each agency regarding personnel, equipment, and liability were described in the agreement. The agreement also granted officers assigned to the Regional T raffic Unit the same powers, duties, privileges, and immunities that are conferred on the police officers of the municipality in which the Unit is operating. Furthermore, each community agreed to bear the expense of the deployments without additional funding.

The compact lead to the designation of the Unit as a "non-profit" entity. This designation has enabled the Unit to receive court-ordered contributions in accordance with Connecticut law. The Unit has received thousands of dollars in court-ordered donations, allowing for the purchase of operational equipment and training materials.

Enforcement efforts were rotated to a different community every month. The resulting enforcement effort in each particular community every seven or eight months was not sufficient enough to create a perception of risk. Though the Unit was not successful in having the desired impact on injury-producing crashes, there were other positive effects: increased enforcement efforts; sharpened officer skills in impaired driving apprehensions; increased media attention; and expanded public information and education efforts.

The Unit has applied for grant monies in 1996 to increase the number of deployments. This additional effort is intended to increase the public's perception of risk and to decrease the number of crashes within the respective communities.

For additional information, contact:

$$
\begin{aligned}
& \text { Chief MurRay J. PendLeton } \\
& \text { Waterford Police D epartment } \\
& 41 \text { Avery Lane } \\
& \text { Waterford, CT } 06385 \\
& \text { Phone: (860) } 442-9451 \\
& \text { Fax: (860)442-2557 }
\end{aligned}
$$

M ulti-jurisdictional programs have also been created in A rkansas, A rizona, California, Florida, Indiana, and N ew York.

M ultiple states have implemented programs across Interstate highways. These projects have been called Operation Span I-10, Operation Western 9, and Operation Crossroads. 


\section{DICKINSON, NORTH DAKOTA}

A fter identifying increases in traffic crashes over several years, the Dickinson Police D epartment implemented a Speed Shatters Lifestrategy to address the problem. W ith a grant from the State Highway Safety Office, the police department embarked on a oneyear public information and enforcement campaign which targeted violations that were identified as contributing factors in these crashes. During the first two months, citations were issued for running stop signs or red lights, speeding, and following too close This intensified enforcement effort contributed to a 13.5 percent reduction in the number of reported traffic crashes.

For additional information, contact:

Capt. Gary J. BanYI

Dickinson Police Department

66 12th Street West

Dickinson, ND 58601

Phone: (701) 264-7759

For information on similar programs, contact:

LT. PAul Tiernan

Teaneck Police D epartment

One Cedar Lane

Teaneck, NJ 07666

Phone: (201) 837-2600

SGT. RICHARD D. WYSS

Iowa City Police Department

410 East Washington Street

Iowa City, IA 52240

Phone: (319) 356-5275

LT. J IM SMITH

Dothan Police Department

210 N orth Saint A ndrews Street

Dothan, AL 36303

Phone: (334) 793-0211

Mas, Ken Howes

Chief Public Information Officer

Florida Highway Patrol

$N$ eill Kirkman Building

A-425

Tallahassee, FL 32399

Phone: (904) 487-3139

\section{SHAWANO COUNTY, WISCONSIN}

On Wisconsin State Highway 29, a two-lane thoroughfare nicknamed "Blood Bath Lane," speed-related fatalities were highly overrepresented. Since the highway is a major route between Minneapolis and Green Bay, drug trafficking was also occurring.

The Shawano County Sheriff's Office, along with the Shawano, Tigerton, and Bonduel Police Departments, established a multijurisdictional task force. Their goal was to reduce speed-related traffic crashes and interdict criminal drug activity along the corridor.

A fter 300 hours of corridor patrols, the task force made five drug arrests, conducted 24 drug searches, and issued 169 traffic citations and 319 warnings. These efforts were conducted with monies made available under a Section 402 grant, along with each agency contributing to the operating costs.

For additional information, contact:

SGT. ROBERT SCHMIDT

Shawano County Sheriff's Office 405 N orth Main Street

Shawano, WI 54166

Phone: (715) 526-3106

Fax: (715) 524-5181

\section{SAN BERNARDINO, CALIFORNIA}

The San Bernardino Police Department, attempting to increase the public's awareness of the dangers of traffic-related crashes, established a T raffic Safety Education Program. The program was funded with a State Office of T raffic Safety grant to increase safety belt use and reduce speed and alcoholrelated crashes.

The grant monies provided for a contract manager, the purchase of two visible display radar trailers, 12 radar units, six preliminary breath testing devices, a driving under the influence (DUI) trailer, a computer, and public information and education materials.

T wo years after implementation, the San Bernardino Traffic Safety Education Program attained the following results:

Reduced speed-related fatal and injury crashes by 32 percent;

$\triangleright$ Reduced DUI property damage-only crashes by 62 percent;

Reduced total fatal and injury crashes by 15 percent; and

$\triangleright$ Increased safety belt use from 48 percent to 71 percent.

For additional information, contact:

TRAFFIC DIVISION

San Bernardino Police D epartment

P.O. Box 1559

San Bernardino, CA 92402

Phone: (909) 383-5011 


\section{MILBRAE, CALIFORNIA}

The community of Millbrae, concerned about the high number of speed-related crashes on several town roads, requested funds from the State Office of T raffic Safety to address the issue. In their grant proposal, the Millbrae Police Department set their goals to reduce speed-related crashes, reduce the blood alcohol concentration (BAC) of DUI arrestees, reduce alcohol-related crashes, and increase safety belt law compliance.

The grant monies purchased a visible display radar trailer, two radar units, and two preliminary breath testing devices. By utilizing these devices in obtaining violations, the M illbrae Police D epartment obtained the following results:

$\triangleright$ Reduced speed-related crashes by 64 percent;

$\triangleright$ Reduced DUI property damage-only crashes by 81 percent;

$\triangleright$ Reduced DUI injury crashes by 75 percent;

$\triangleright$ Reduced the average BAC of DUI arrestees from 0.18 to 0.15 ; and

$\triangleright$ Increased safety belt use from 76.5 percent to 86.5 percent.

For additional information, contact:

SGT. TED SILVAS

Millbrae Police Department

P.O. Box 850

Millbrae, CA 94030

Phone: (415) 259-2300

\section{SAN GABRIEL, CALLFORNIA}

San Gabriel received a grant from the State Office of T raffic Safety to develop and implement a community traffic safety program to address the increased traffic congestion in urbanized areas. The goal of this program was to fund three sworn motorcycle officers to focus on hazardous citations, occupant protection violations, and DUI checkpoints.

The grant monies funded the salaries of three officers, and purchased four computers, three laser devices, a visible display radar unit, and public information and education materials.

In under two years, the San Gabriel Police Department T raffic Safety Program was successful in:

$\triangleright$ Reducing alcohol-related crashes by 21 percent:

$\bowtie$ Reducing DUI (property damage-only) crashes by 80 percent;

$\rightarrow$ Reducing total fatal and injury crashes by 13 percent; and

$\triangleright$ Increasing safety belt use from 77 percent to 89 percent.

For additional information, contract:

SGT. J OHN TUOSTO

San Gabriel Police Department

P.O. Box 130

San Gabriel, CA 91778

Phone: (818) 308-2828

\section{INDIANA}

Indiana crash data revealed what motorists who brave the dangerous Interstate 94 already knew -- there are too many crashes involving tractor trailers.

Several Indiana State Police troopers will receive special training in an effort to crack down on speeding truckers in the northwest corner of the state The training will certify troopers to conduct Level 3 inspections, also known as "driver only" inspections. These inspections are a roadside examination of a driver's commercial driver's license, medical certification and waiver (if applicable), record of duty status, hours of service, safety belt use, and vehicle inspection report. This means that once a moving violation, such as speeding or following too closely, is witnessed, the trucker would be pulled over and this information would be checked and verified. The training involves teaching the troopers how to look for signs of falsifying records.

In Indiana, statewide crashes involving heavy commercial motor vehicles increased by 2,100 in 1994 over 1993, although fatal crashes decreased. Lloyd Jennings, Superintendent of the Indiana State Police, states, "We feel that with the trend of increased crashes, we need to get a handle on it before the death rate goes up with the crashes." In 1994 alone, there were nearly 19,000 crashes involving tractor trailers in Indiana. 
While state troopers have conducted safety inspections on tractor trailers for several years, Superintendent J ennings said he and others felt it was time to focus more on the drivers.

\section{TIGARD, OREGON}

M any local communities were experiencing problems resulting from speeding vehicles in their neighborhoods. In addition to contributing to increased traffic crashes, these speeding vehicles were hazardous to both bicyclists and pedestrians. In some areas, these issues caused concern due to the number of young children whose safety was compromised each time they rode their bicycles or went for a walk. Since police officers cannot make every vehicle slow down, those who live in these communities faced a dilemma.

$M$ any residents and communities looked to other methods of slowing down traffic without disrupting the neighborhoods or the residents. The new approach is called "traffic calming."

Traffic calming employs several techniques designed to alter hazardous traffic behavior. These techniques include:

$\triangleright$ N ARROW N EIGHBORHOOD STREETS: narrow roadways slow traffic while wider lanes encourage greater speed;

TRAFFIC CIRCLES: the interruption of a motorist's "sight line" both narrows the road and causes drivers to slow down;

$\triangleright$ SPEED HUM PS: slightly raised sections in the road designed to be wide enough for both sets of wheels to be on top of the hump at once. Speed humps allow cars to travel comfortably at, but not above, the posted speed limit;

$\triangle N$ ECKDOW N S: islands that intrude into the roadway to form a narrow "gate" through which drivers must pass; and

SIG N S: used to remind drivers that the neighborhood and local streets are not designed for making a faster commute.
$M$ any communities in the northwest section of the county have been successful in implementing these techniques, which have contributed to a noticeable reduction in the speed of passing vehicles. These techniques should also reduce the number of crashes on these roadways.

For additional information, contact: SENSBBE TRANSPORTATON OPTIONS For PEOPE (STOP) 15405 S.W. 116th Avenue \#202B

Tigard, OR 97224-2600

Phone: (503) 624-6083

Fax: (503) 620-5989

\section{MOBIIE, ALABAMA}

A fter experiencing a substantial increase in crash-related fatalities and injuries, the M obile Police Department initiated "Operation Zero Tolerance." The program sought to:

$\triangleright$ Identify the most frequent traffic violations contributing to the rising trend in crashes and injuries;

$\triangleright$ Identify specific target areas and crash data in Mobile; and

$\triangle$ D evelop and implement strategies to address these traffic problems with the most efficient use of available resources.

Following an intensive media and public information campaign, a strict enforcement effort was conducted. A fter one year, fatalities were reduced to 22 in 1993 and 10 in 1994, as compared to 37 fatalities in 1992. Safety belt usage increased from 38 to 85 percent. It was also estimated that Operation Zero Tolerance produced an economic savings of over \$11 million.

For additional information, contact: TRafFIC SAFETY UNIT

M obile Police D epartment

2460 Government Boulevard

M obile, A L 36606

Phone: (334) 434-1860

Fax: (334) 434-1725

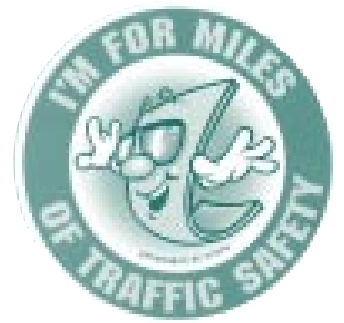

\section{SOUTH CAROLNA}

A popular campaign developed in South Carolina (and also used in Georgia) to improve highway safety features an animated character named "M iles." This animated and articulate yellow centerline stripe comes alive to actively inform and teach highway users about various highway safety topics. Extensive planning, including focus group research, was used in developing the M iles campaign.

A major element of the educational campaign is the "Miles of Safety" booklet. The booklet contains 50 traffic safety tips on various highway safety topics.

Specially emphasized M iles topics to date have included speeding, merging, child safety belt use, and sharing the road with large trucks. Each professionally prepared campaign topic includes radio and animated television advertisements. Billboard and newspaper advertisements and a variety of novelty items, such as t-shirts, key chains, caps, and bumper stickers, are also used.

The M iles character, including a costumed Miles, is extremely popular at public events, such as fairs, schools, and sporting events, and draws extensive news coverage when a new television advertisement is released.

A nyone nationwide may call the toll free telephone number (800-OK-MILES) to request the booklet and a bumper sticker. The voice of Miles guides the caller through the ordering process. Over 10,000 callers have requested information. $M$ any callers request multiple copies of the M iles materials for business, civic groups, and school use. Go ahead -- give Miles a call. 
South Carolina is interested in partnering with other states on the M iles campaign, as they did with Georgia. The partners would receive the use of all developed Miles materials in exchange for producing materials for a new specific campaign topic. This partnering provides a cost-effective and unified education approach which can provide widespread recognition of the character and the highway safety messages.

For additional information, contact:

$$
\begin{aligned}
& \text { J AMIE HAWKINS } \\
& \text { South Carolina Department of } \\
& \text { Public Safety } \\
& \text { Phone: }\left(\begin{array}{l}
800) \\
803) \\
809-9876 \text { or } \\
896-8756
\end{array}\right.
\end{aligned}
$$

\section{CHATTANOOGA, TENNESSEE}

A fter receiving a grant from the Governor's Highway Safety Office, an intensive speed enforcement program was implemented for the entire city, along with targeting 12 highcrash areas. After the initial public information and education campaign, a daily schedule of enforcement activities was published for each wave of enforcement. However, timetables were not publicized and additional locations were covered, creating the illusion that more enforcement teams existed.

Ten waves of data collection were conducted over the 43-month enforcement campaign. The evaluation of eight locations was conducted using modified radar equipment that operated on an unobtrusive frequency that did not trigger radar detectors. The evaluation revealed that speeding (vehicles exceeding the speed limit by at least $10 \mathrm{mph}$ ) was reduced by approximately 10 percent. These reductions continued through the last wave of measurements, even though the program was not continuous during that period. A 20 percent reduction in injury and speed-related crashes was also observed.

For additional information, contact:

CAPT, LEE J. HIIXSS

Chattanooga Police Department

3300 A mnicola Highway

Chattanooga, TN 37406

Phone: (423) 698-9591
ALASKA, IDAHO, OREGON, AND WASHINGTON

The Office of M otor Carriers (OMC) in the Region 10 states of A laska, Idaho, Oregon, and Washington are now better informed about the locations of serious truck crashes in their states. In an outreach effort to reduce crashes by informing the public of high truck crash locations, Region 10 collected commercial motor vehicle (CM V) crash data, identified the most serious truck crash locations in each state, and created a brochure for public dissemination identifying these locations. The OMC Region 10 Crash Data Team created a proactive, visual, driver-oriented brochure designed to inform commercial motor vehicle drivers about the most serious (high frequency) crash locations in the Pacific N orthwest. The brochure is beneficial to the motor carrier industry as a preventive safety alert, as well as a tool in reducing the crash rates in the Region 10 states. The two main objectives are:

$\triangleright$ Public awareness (with the commercial driver as the initial target audience); and

$\triangleright$ Crash reduction.

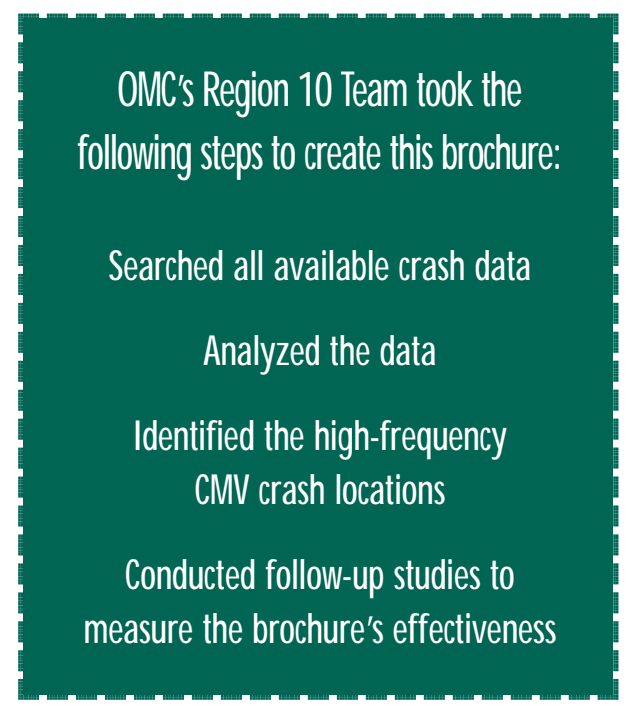

To measure the effectiveness of this pubic awareness project, the following will be studied: $\triangleright$ Industry feedback and interest, based on brochure requests, objective comments, and voluntary reprinting and distribution by the industry;

$\triangleright$ Establishing and nurturing new partnerships and strengthening old partnerships -- the degree of increased interaction with local law enforcement agencies, state highway departments, local magistrates, insurance companies, and trucking associations;

$\triangleright$ Effective use of personnel and resources -enforcement efforts in these high-crash locations which suggest that fatigue may be the primary causal factor; Hours of Service strike forces with state personnel and safety investigators placed at strategic locations along these corridors to collect additional data for the fatigue studies; provide carriers with more effective crash countermeasures;

$\triangleright$ Creating new areas for study and consideration -- collection and analysis of crash data at these locations to see if a profile of the driver/carrier most likely to be involved in an crash emerges (e.g.: out-of-state driver on first trip to this state); and

$\triangleright$ Data tracking and analysis -- collection and comparison of crash data in these corridors using the ratio of CMV crashes per CM V road miles traveled (traffic density) over the next three-to-five year period; comparison of the number and type of moving violations issued versus the number of crashes in these locations.

For additional information (and copies of the brochure), contact:

OfFICE OF Motor CARriers

The Equitable Center

530 Center Street, N.E.

Suite 100

Salem, OR 97301

Phone: (503) 399-5775 